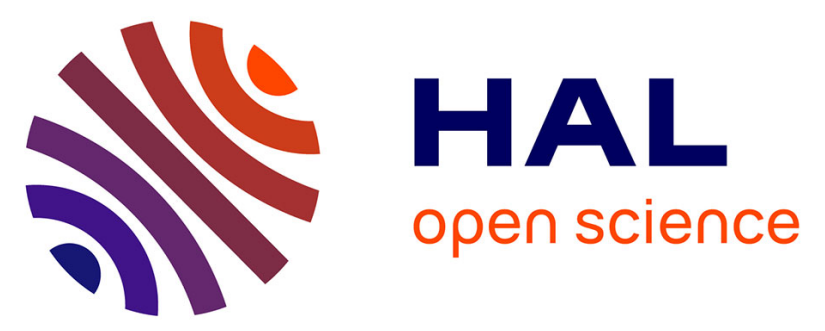

\title{
Optimization of the optical properties of nanostructured silicon surfaces for solar cell applications
}

Di Zhou, Yan Pennec, Bahram Djafari-Rouhani, Odile Cristini-Robbe, Tao

Xu, Yannick Lambert, Yves Deblock, Marc Faucher, Didier Stiévenard

\section{- To cite this version:}

Di Zhou, Yan Pennec, Bahram Djafari-Rouhani, Odile Cristini-Robbe, Tao Xu, et al.. Optimization of the optical properties of nanostructured silicon surfaces for solar cell applications. Journal of Applied Physics, 2014, 115, pp.134304. 10.1063/1.4870236 . hal-00974457

\section{HAL Id: hal-00974457 \\ https://hal.science/hal-00974457}

Submitted on 28 Jul 2021

HAL is a multi-disciplinary open access archive for the deposit and dissemination of scientific research documents, whether they are published or not. The documents may come from teaching and research institutions in France or abroad, or from public or private research centers.
L'archive ouverte pluridisciplinaire HAL, est destinée au dépôt et à la diffusion de documents scientifiques de niveau recherche, publiés ou non, émanant des établissements d'enseignement et de recherche français ou étrangers, des laboratoires publics ou privés. 


\title{
Optimization of the optical properties of nanostructured silicon surfaces for solar cell applications
}

\author{
Di Zhou, ${ }^{1}$ Y. Pennec, ${ }^{1}$ B. Djafari-Rouhani, ${ }^{1}$ O. Cristini-Robbe, ${ }^{2}$ T. Xu, ${ }^{3}$ Y. Lambert, ${ }^{1}$ \\ Y. Deblock, ${ }^{1}$ M. Faucher, ${ }^{4}$ and D. Stiévenard ${ }^{1, a)}$ \\ ${ }^{1}$ Institut d'Electronique et de Microélectronique et de Nanotechnologies, IEMN, (CNRS, UMR 8520), \\ Groupe de Physique, Cité scientifique, avenue Poincaré, 59652 Villeneuve d'Ascq, France \\ ${ }^{2}$ PHLAM, UMR8523, Université de Lille 1, 59652 Villeneuve d'Asq Cedex, France \\ ${ }^{3}$ Key Laboratory of Advanced Display and System Application, Shanghai University, 149 Yanchang Road, \\ Shanghai 200072, People's Republic of China \\ ${ }^{4}$ Institut d'Electronique et de Microélectronique et de Nanotechnologies, IEMN, (CNRS, UMR 8520), \\ Groupe NAM6, Cité scientifique, avenue Poincaré, 59652 Villeneuve d'Asq, France
}

(Received 21 February 2014; accepted 21 March 2014; published online 1 April 2014)

\begin{abstract}
Surface nanostructuration is an important challenge for the optimization of light trapping in solar cell. We present simulations on both the optical properties and the efficiency of micro pillars-MPs_-or nanocones_- NCs_-silicon based solar cells together with measurements on their associated optical absorption. We address the simulation using the Finite Difference Time Domain method, well-adapted to deal with a periodic set of nanostructures. We study the effect of the period, the bottom diameter, the top diameter, and the height of the MPs or NCs on the efficiency, assuming that one absorbed photon induces one exciton. This allows us to give a kind of abacus involving all the geometrical parameters of the nanostructured surface with regard to the efficiency of the associated solar cell. We also show that for a given ratio of the diameter over the period, the best efficiency is obtained for small diameters. For small lengths, MPs are extended to NCs by changing the angle between the bottom surface and the vertical face of the MPs. The best efficiency is obtained for an angle of the order of $70^{\circ}$. Finally, nanostructures have been processed and allow comparing experimental results with simulations. In every case, a good agreement is found. (C) 2014 AIP Publishing LLC. [http://dx.doi.org/10.1063/1.4870236]
\end{abstract}

\section{INTRODUCTION}

Semiconductor micropillars (MPs) or nanowires (NWs) are more and more involved in the fabrication of devices based on the photogeneration of free carriers, ${ }^{1-5}$ mainly due to their low optical reflectance when used as thin films or their high efficiency to collect carriers in radial junction as their diameter can be lower than the diffusion length of the minority carriers. ${ }^{6}$ Optical properties of individual NWs have been studied. ${ }^{7-9}$ For example, as NWs have typically a smaller diameter than thin films made up of equivalent materials, one could expect shorter carrier transit times, 6,7 a crucial property for increasing the speed of photodetectors or the photoconductive gain of solar cells. Mainly NWs arrays are used and their optical properties have been experimentally studied. ${ }^{10-22}$ Optical absorption of silicon NWs arrays has also been simulated. ${ }^{23-36}$ In fact, the optical properties of NWs arrays and accordingly the so called ultimate efficiency $\alpha$ (defined by the assumption that each absorbed photon with energy greater than the band gap produces one and only one electron-hole pair with energy hc/ $\lambda_{\mathrm{g}}$, where $\lambda_{\mathrm{g}}$ is the wavelength corresponding to the silicon band gap, $h$ the Planck's constant and $\mathrm{c}$ the light velocity in air) depend of many parameters, such as the length, the diameter, the filling factor

\footnotetext{
a) Author to whom correspondence should be addressed. Electronic mail: didier.stievenard@isen.fr
}

(ratio between the diameter and the period), or periodicity of the NWs. So, it is a complex multiparameter problem. For example, the study of the influence of the diameter can affect the filling factor and the periodicity of the array. In another way, the filling factor can be kept constant with diameter and period varying proportionally. While generally people arbitrary assign a value to one parameter (length, diameter, periodicity, or filling factor) and study the optical properties versus the other parameters, a general overview of the role of the geometrical parameters is still missing. Among the puzzling data, some clear feature emerges as a high efficiency when the ratio of the diameter (D) over the period (P) is greater than 0.5 with a maximum for 0.8 (see Refs. 23 and 25). Finally, just a few papers present both simulations and experimental verifications. ${ }^{15,16,29,31}$

In this paper, we propose simulations on the optical reflectance and efficiency of MP arrays, extended to $\mathrm{NC}$ arrays by varying the shape of MPs, with all the parameters taken into account at the same time. The objective is to give a general trend on the behavior of the efficiency of the solar cell versus the whole geometrical parameters. We first study the influence of the diameter and of the period. We therefore study the influence of the length and finally we study together the length, the period, and the diameter. The MP properties are extended to NCs. Finally, we present also a few experimental results which are in a good agreement with the simulations. 


\section{THEORETICAL ANALYSIS}

\section{A. Finite difference time domain method}

The calculations have been performed on periodic hexagonal (or triangular) array of vertical MPs on Si substrate using a homemade Finite Difference Time Domain (FDTD) method. The structure of the 3D unit cell is shown in Fig. 1. The incident source is placed in the air medium and propagates along the z-direction, perpendicularly to the periodic structure. The Maxwell's equations are solved by discretizing both time and space and by replacing derivatives with finite differences. Perfect Matching Layers (PML) are applied at the finite boundaries of the box, along $\mathrm{z}$, in order to avoid reflections of outgoing waves. ${ }^{37}$ Along the $x$ and $y$ direction, the unit cell is repeated periodically and the structure is supposed to be finite along the $z$ direction. Periodic boundary conditions (PBC) are applied on both upper and lower sides of the unit cell to build the periodic structure. Fig. 1(b) represents a cross section in the (x,y) plane of the 3D unit cell through the cylinders. For the hexagonal lattice geometry of the MPs, a rectangular unit cell with two cylinders per unit cell has been chosen to respect the square meshing used in the FDTD code. The application of the periodic boundary conditions on each side of the unit cell leads to a hexagonal array of pillars. The symmetry of the lattice insures a quasi-isotropy in the plane of the structure. The absorption is calculated from the reflection and transmission coefficients, respectively, recorded in the air medium and at the surface of the silicon substrate, following the equation $A=1-(T+R)$.

The space is discretized in both $x$ and $y$ directions using a mesh interval equal to $\Delta x=\Delta y=1 \mathrm{~nm}$. The equations of motion are solved with a time integration step $\Delta t=\Delta x / 4 c$ and a number of time steps equals to $2,{ }^{20}$ which is the necessary tested time for a good convergence of the numerical calculation. The incoming pulse is generated at the left part of the unit cell (in the air medium), by a current source perpendicular to the $\mathrm{z}$ axis and having a planar profile. The current is generated during a short period of time in such a way as to excite the electromagnetic waves in the frequency domain of interest. Then, the reflection and transmission spectra recorded during the time are Fourier-transformed to obtain $\mathrm{R}$ and $\mathrm{T}$ as a function of frequency and then deduce the absorption as $\mathrm{A}=1-\mathrm{T}-\mathrm{R}$.
In our calculation, the frequency-dependent complex permittivity of silicon is described by the Lorentz oscillator model $^{38}$

$$
\boldsymbol{\varepsilon}(\boldsymbol{E})=\boldsymbol{\varepsilon}_{1}(\infty)+\sum_{i=1}^{4} \frac{\boldsymbol{A}_{\boldsymbol{i}}}{\boldsymbol{E}_{\boldsymbol{i}}^{2}-\boldsymbol{E}^{2}+\boldsymbol{j} \boldsymbol{E} \boldsymbol{\Gamma}_{\mathrm{i}}},
$$

where $\varepsilon_{1}(\infty)$ is the high frequency dielectric constant, $A_{i}, \Gamma_{\mathrm{i}}$, and $E_{i}$ are, respectively, the amplitude, the damping factor, and the resonant energy of the ith oscillator. The parameters are taken from Ref. 39. They allow fitting the dielectric permittivity of silicon in the range from 0.2 to $4 \mathrm{eV}$.

In order to estimate not only the reflectance or absorption properties of Si MPs, we calculate the so called ultimate efficiency $\alpha$, which is defined as the efficiency of a solar photovoltaic cell with crystalline silicon film as the active layer at $0 \mathrm{~K}$ when each photon with energy greater than the band gap of crystalline silicon produces one electron-pair. It is given by the equation

$$
\boldsymbol{\alpha}=\frac{\int_{0}^{\lambda_{\mathrm{g}}} \mathbf{I}(\lambda) \mathbf{A}(\lambda) \frac{\lambda}{\lambda_{\mathrm{g}}} \mathbf{d} \lambda}{\int_{0}^{\infty} \mathbf{I}(\lambda) \mathbf{d} \lambda},
$$

where $\mathrm{I}(\lambda)$ is the solar irradiance spectrum, $\mathrm{A}(\lambda)$ is the silicon absorption, and $\lambda_{\mathrm{g}}$ is the wavelength corresponding to the energy band gap of the silicon. For solar intensity, we used the AM 1.5 spectrum.

In the next part, we present the general theoretical trends for the absorption $\mathrm{A}(\lambda)$ and the ultimate efficiency $\alpha$ as a function of the geometrical parameters of the Si MP arrays. Many parameters are involved in the structure, namely, the diameters, the period, and the length of the pillars.

\section{B. Theoretical results}

\section{Effect of the diameter}

We first illustrate the properties of absorption for a variation of the diameters of the MPs. Intuitively, one can expect that the absorption is linked to the volume of the materials, hence to the diameter of the MPs.

Figure 2(a) gives the absorption of a Si MPs array of period $380 \mathrm{~nm}$, for a constant length $\mathrm{L}$ of the pillars of

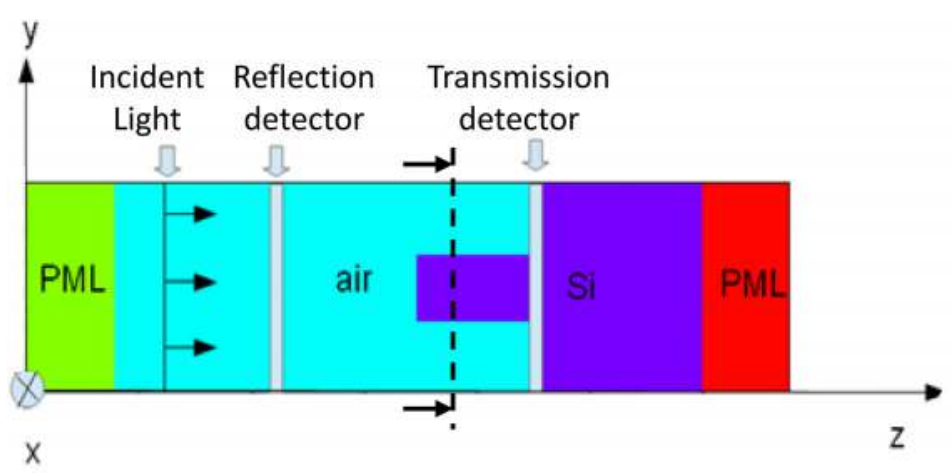

(a)

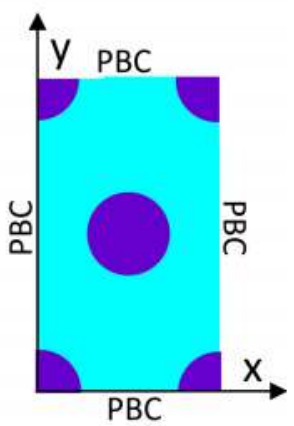

(b)
FIG. 1. Schematic representation of the unit cell used for the calculation. The positions of the detectors for the incident, reflection, and transmission calculations are presented (a) in the $(y, z)$ plane and $(b)$ in the $(x, y)$ plane. The boundaries conditions are indicated as PBC and PML. 


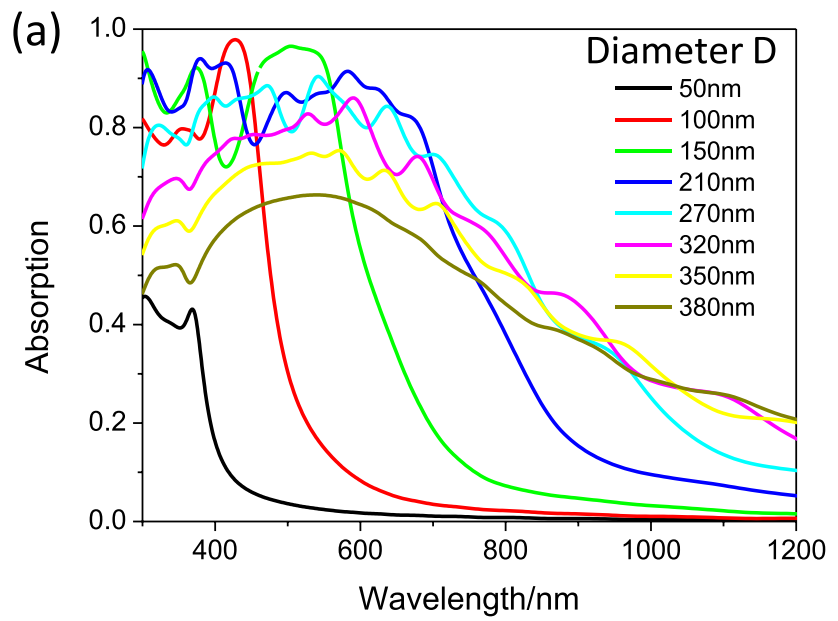

(b)
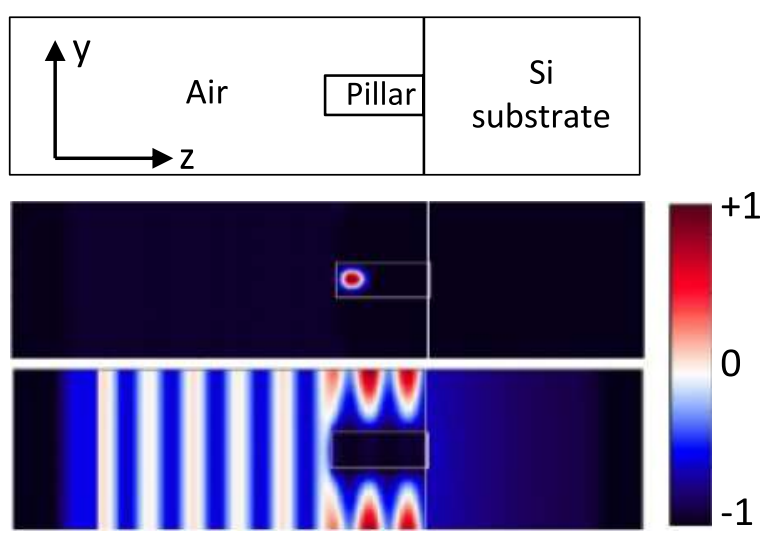

FIG. 2. (a) Absorption spectra of MPs as a function of the diameter ranging from 50 to $380 \mathrm{~nm}$, with the same length (1000 nm) and period (380 nm) of the MPs; (b) schematic view of the unit cell and distributions of the electromagnetic field intensity for a monochromatic excitation in the steady state at the wavelength of $509 \mathrm{~nm}$ (upper part) and a wavelength of $1200 \mathrm{~nm}$ (lower part).

$1000 \mathrm{~nm}$ and a diameter ranging from 50 to $380 \mathrm{~nm}$. We can see that at low wavelengths, the absorption is maximal before dropping to almost zero for larger wavelengths. We define the threshold wavelength $\lambda_{\text {th }}$ as the wavelength for which the absorption is equal to half its maximum. Figure 2(b) shows the distribution of the electromagnetic field intensity inside the unit cell, for a diameter of the MP, $\mathrm{D}=150 \mathrm{~nm}$, at two different wavelengths, respectively, before (upper part) and after (lower part) the threshold $\left(\lambda_{\text {th }}=600 \mathrm{~nm}\right.$ ). For a wavelength of $509 \mathrm{~nm}$ (Fig. 2(b)-upper panel), the electromagnetic field is localized inside the MP leading to a maximum of absorption, whereas for an illumination at $1200 \mathrm{~nm}$, the electromagnetic field is outside the MP (Fig. 2(b) lower panel), and the absorption is minimal. It means that the localized absorption through the pillars is only possible for a set of wavelengths lower than a critical value beyond which the absorption becomes weak. In this latter case, the wavelength does not penetrate anymore inside the pillar.

From Figure 2(a), we deduce the evolution of the threshold wavelength $\lambda_{\text {th }}$ with the diameter (Figure 3(a)), which increases in agreement with previous results. ${ }^{8}$ For diameters larger than $300 \mathrm{~nm}$, a phenomenon of saturation is observed due to a close packing of the MPs inside the array. For these large diameters, the benefit of the nanostructuration, which normally increases the photons optical path, is lost. In the simulation, the maximum value of the diameter is $380 \mathrm{~nm}$, which corresponds to the value of the period. It corresponds to a close packed cylinders array, not far from bulk material.

While the optical absorption is a physical key parameter, it is nevertheless not sufficient to master an optimized nanostructuration of the surface. An additional information is contained in the ultimate efficiency, as defined in Eq. (2). Indeed, it gives a property which is not far from the photocurrent and therefore, the yield of a solar cell as the solar irradiance spectrum is taken to be the AM1.5G spectrum. Fig. 3(b) gives the ultimate efficiency calculated versus the diameter, ranging from 50 to $380 \mathrm{~nm}$. The curve has a maximum for a diameter $\mathrm{D}$ of the order of $270 \mathrm{~nm}$, i.e., a ratio $\mathrm{D} / \mathrm{P}=0.7$. When the diameter tends towards the period
(380 $\mathrm{nm}$ in Fig. 3(b)), the efficiency tends to the value of a bulk layer (red dashed line) with a thickness equal to the length of the MPs. It is interesting to note that the efficiency of the MPs is always better than the one of the bulk layer with the same equivalent volume (red points), clearly showing the benefice of the nanostructuration. Moreover, there is a critical diameter (in that case, $210 \mathrm{~nm}$ ) above which the efficiency of the MPs exceeds the efficiency of a film with the same thickness as the length of the MPs (red horizontal line).

\section{Effect of the period and the length}

Fig. 3(c) shows the ultimate efficiency calculated versus the period for a diameter $\mathrm{D}=210 \mathrm{~nm}$ and a length $\mathrm{L}=1000 \mathrm{~nm}$ of the MPs. As for the study versus the diameter, we observe that the efficiency of an array of MPs is always better than the associated bulk layer with the same thickness (red points). In fact, in that case, the volume is constant and therefore, for the equivalent bulk layer, the thickness decreases accordingly to the inverse of the period. In the case studied in Fig. 3, a maximum of efficiency is found for a period of $260 \mathrm{~nm}$, i.e., $\mathrm{D} / \mathrm{P}=0.8$, a ratio very close to the one found in the previous section. So, we find that the pertinent key parameter is not the diameter or the period alone but the ratio $\mathrm{D} / \mathrm{P}$.

For given diameter and period, we study the influence of the length on the efficiency. As illustrated in Figure 3(d), (diameter of $270 \mathrm{~nm}$ and period of $380 \mathrm{~nm}$ ), the efficiency increases rapidly for small lengths and then saturates for higher ones. The gain obtained with respect to a bulk layer having the same volume is greater for small lengths than for high values of $L$. In other words, there is a gain associated with the nanostructuration as far as the length $L$ remains relatively small, whereas for larger lengths we detect the bulk effect associated with the volume of MPs.

A general approach is summarized in the following part.

\section{Efficiency abacus versus the length, the diameter, and the period of MPs}

Fig. 4 summarizes the combined effects of the three parameters: diameter, period, and length on the efficiency. We 
(a)
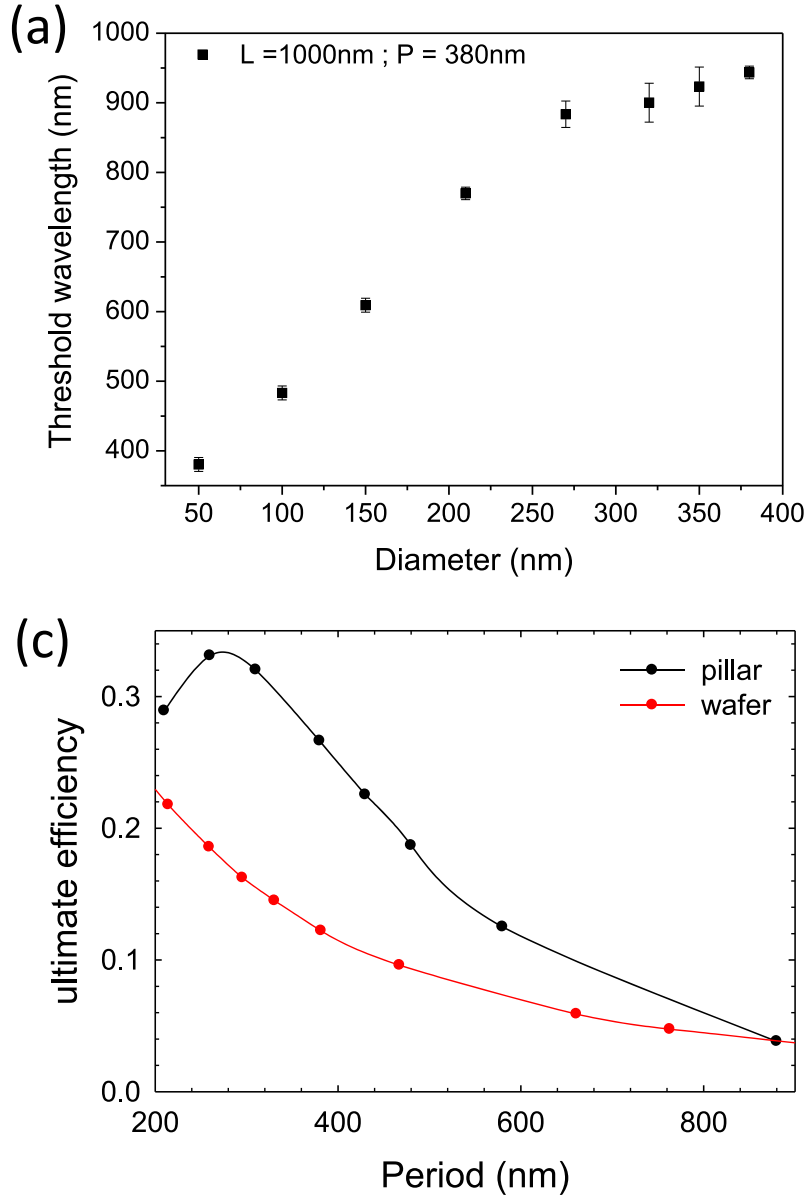

(b)
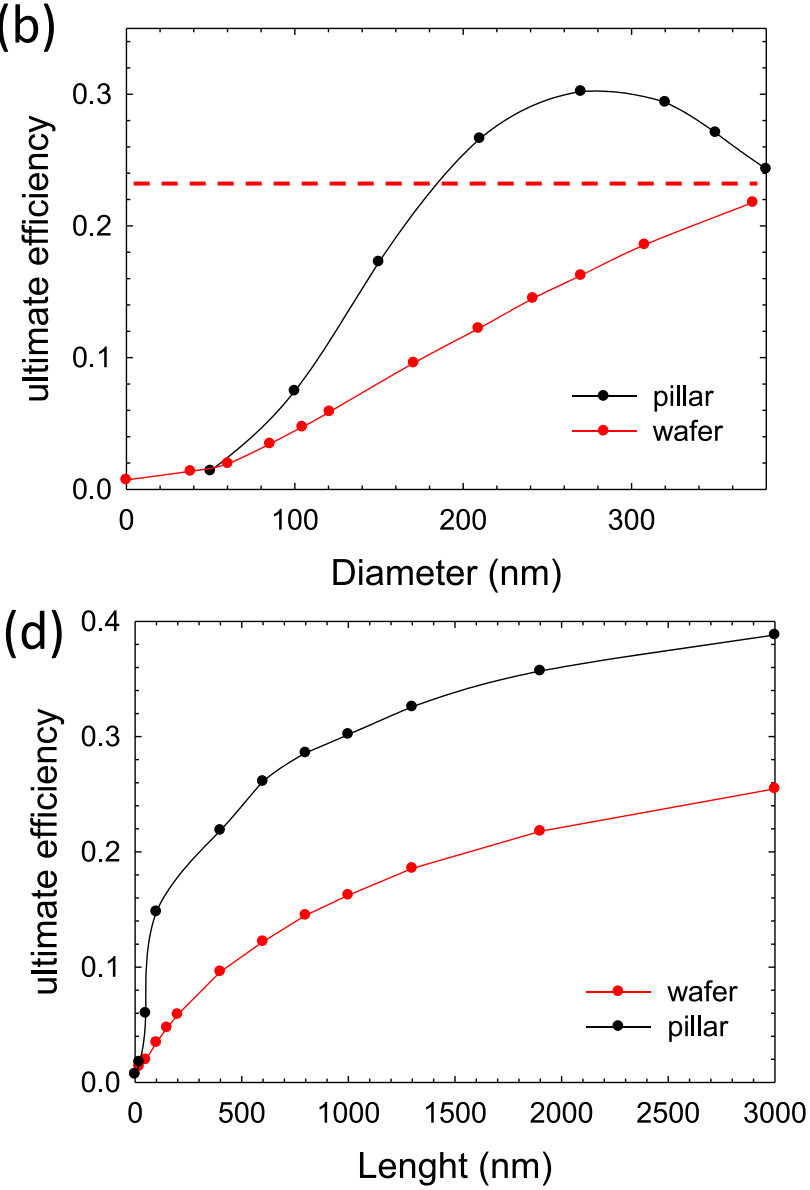

FIG. 3. (a) Evolution of the threshold wavelength as a function of the diameter $(\mathrm{P}=380 \mathrm{~nm}$, L $=1000 \mathrm{~nm})$. Ultimate efficiency versus (b) the diameter $(P=380 \mathrm{~nm}, \mathrm{~L}=1000 \mathrm{~nm}$, (c) the period $(\mathrm{D}=210 \mathrm{~nm}, \mathrm{~L}=1000 \mathrm{~nm})$, and $(\mathrm{d})$ the length of the MPs $(P=380 \mathrm{~nm}, \mathrm{D}=270 \mathrm{~nm})$. In figure $(\mathrm{b})$, the horizontal dashed line represents the ultimate efficiency for a silicon wafer of same thickness than the pillar.

have chosen three values of the period $(380,600$, and $900 \mathrm{~nm}$, respectively, labeled A, B, and C in Fig. 4). For each period, the length varies from 50 to $3000 \mathrm{~nm}$ and the diameters vary from $50 \mathrm{~nm}$ (part A), $60 \mathrm{~nm}$ (part B), and $90 \mathrm{~nm}$ (part C) up to its maximum possible value $(\mathrm{D}=\mathrm{P})$. For the three periods, and independently of the length, the best efficiency is obtained for a ratio $\mathrm{D} / \mathrm{P}=0.7-0.8$. Of course, for a given $\mathrm{D} / \mathrm{P}$ ratio, the efficiency varies with the

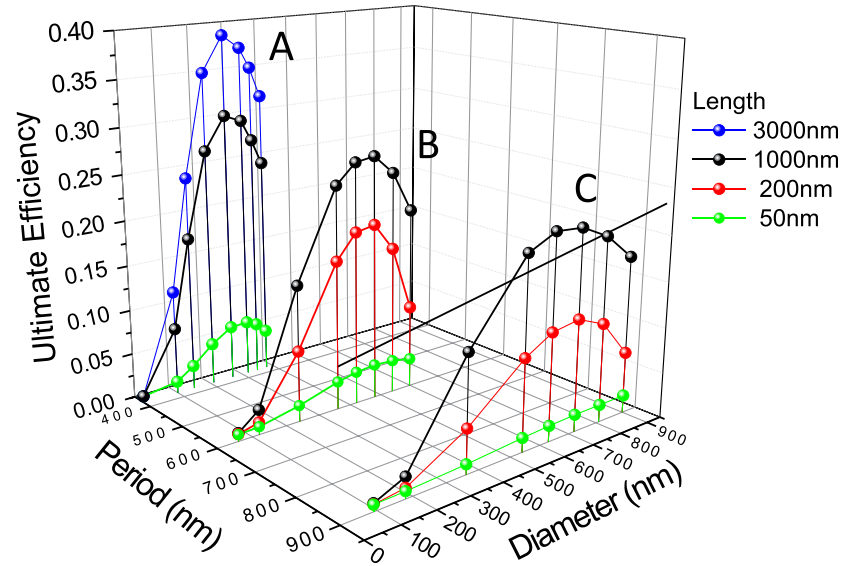

FIG. 4. Ultimate efficiency versus the period, the diameter and the length of the MP's. length. The ratio $\mathrm{D} / \mathrm{P}$ appears definitely as a key parameter: in order to get a maximum of efficiency, the ratio $\mathrm{D} / \mathrm{P}$ must be ranged between 0.7 and 0.8 for a given length. Another question is to know, for a same filling fraction, whether it is more efficient to cover the surface with bigger or smaller diameter MPs. This is illustrated in the next section.

\section{Large or small MP diameters, keeping $D / P=0.7-0.8$}

The configuration "small diameters" or "large diameters," for a given D/P ratio is illustrated Figs. 5(a) and 5(b), respectively. Keeping $\mathrm{D} / \mathrm{P}=0.7$, and a length of $1000 \mathrm{~nm}$, we have calculated the efficiency for different pairs $(D, P)$, from small to large $\mathrm{D}$ and $\mathrm{P}$. We chose the following pairs: $(68,95) \mathrm{nm},(135,190) \mathrm{nm},(270,380) \mathrm{nm},(540,760) \mathrm{nm}$, and $(1080,1520) \mathrm{nm}$. The associated efficiencies are given in Fig. 5(c) where one can easily notice that the best efficiencies are obtained for smaller diameters and, accordingly, periods. For the higher pairs (D $>540 \mathrm{~nm}, \mathrm{P}>760 \mathrm{~nm}$ ), the efficiency of the array moves exactly toward the equivalent bulk layer, with the same length.

\section{From micropillars to nanocones}

Micropillars are special instances of nanocones (NCs), where the top diameter is equal to the bottom diameter. So, 


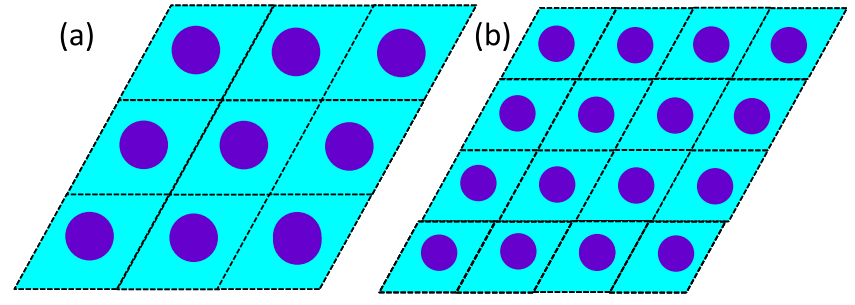

(c)

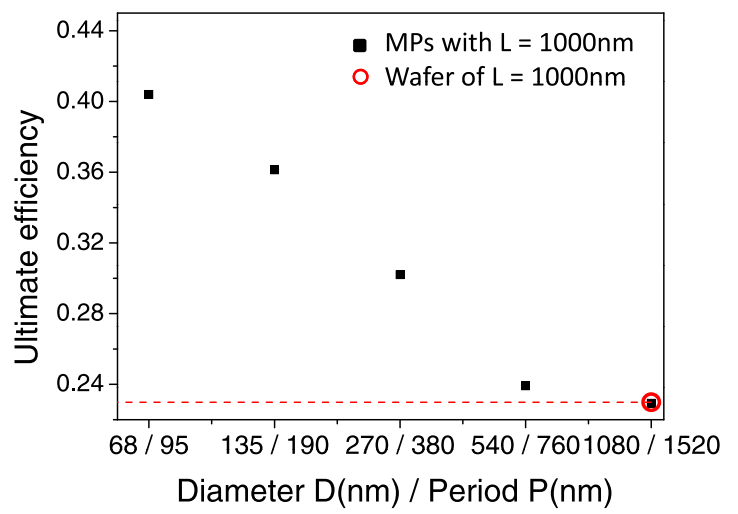

FIG. 5. Schematic representation of large (a) or small (b) diameters keeping the same ratio $\mathrm{D} / \mathrm{P}=0.7$, (c) efficiency versus different diameters with the ratio $\mathrm{D} / \mathrm{P}=0.7$ and for a length of $1000 \mathrm{~nm}$. The different diameter/period $(\mathrm{D} / \mathrm{P})$ are: $(68 / 95 \mathrm{~nm}),(135 / 190 \mathrm{~nm}),(270 / 380 \mathrm{~nm}),(540 / 760 \mathrm{~nm})$, and $(1080 / 1520 \mathrm{~nm})$. A wafer with the same thickness has the same efficiency as the $(1080 / 1520 \mathrm{~nm})$ array. the properties of micropillars can be easily extrapolated to NCs. When fixing the bottom diameter and height, nanocones of different shapes are obtained by rotating the lateral sides with the angle $\theta$ (Fig. 6(a)). Fig. 6(b) gives the efficiency of NCs versus the angle $\theta$ (square solid dots). We take the set of parameters for the nanocone: a bottom diameter of $\mathrm{D}=704 \mathrm{~nm}$, a height of $350 \mathrm{~nm}$, and a period of $\mathrm{P}=880 \mathrm{~nm}$. At a first glance, NCs display only better efficiencies than MPs (corresponding to $\theta$ equal $90^{\circ}$ ) when the angle $\theta$ is close to $90^{\circ}$ with the best angle around $85^{\circ}$. However, to explain and understand this behavior, two effects have to be distinguished. First, there is a shape effect associated with the nanocones, namely a gradual change in the effective optical index from top to bottom, resulting in a better adaptation for the absorption of the electromagnetic waves. When $\theta$ is greater than $90^{\circ}$ (not shown here), the shape of the cone is less adapted for the absorption and the efficiency decreases. When $\theta$ decreases, well below $90^{\circ}$, there is also a dramatic decrease of the efficiency. However, here there is a second effect which produces the decrease of the absorption and hence NC efficiencies, namely, the diminution of the volume due to the variation of $\theta$. Therefore, in order to separate the shape and volume effects, we have calculated the efficiency of an equivalent volume of silicon layer (circular dots in Fig. 6(b)) with the same volume than the NCs array associated with a given $\theta$ angle and we have plotted the ratio $\alpha_{\text {cones }} / \alpha_{\text {wafer }}$ in Fig. 6(c), where $\alpha_{\text {cones }}$ and $\alpha_{\text {wafer }}$ are the efficiencies of the NCs and bulk layers, respectively. This ratio represents the exact gain obtained with NCs array compared to a bulk layer with the same volume. This

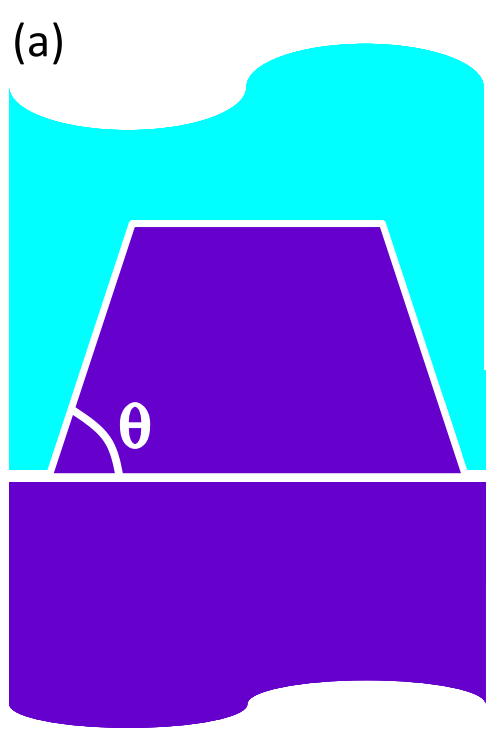

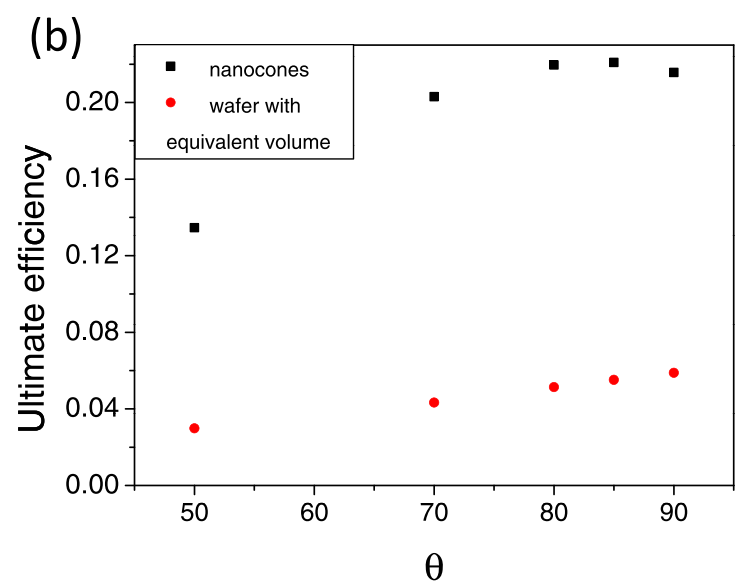

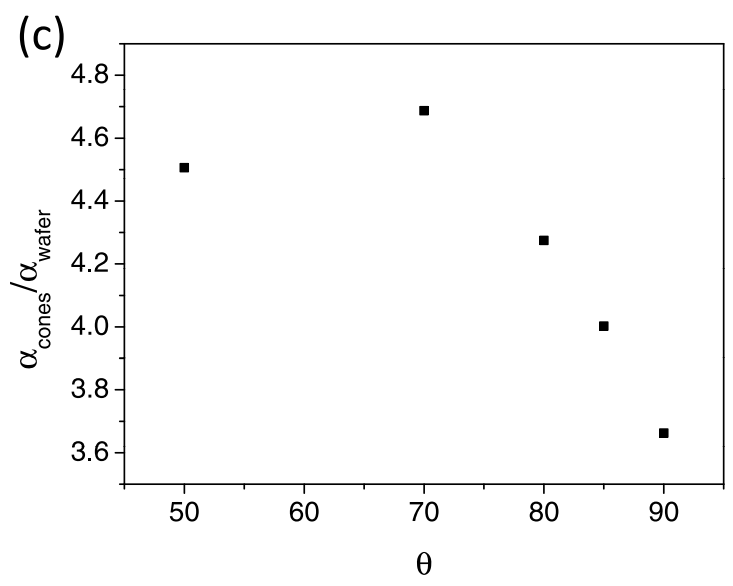

FIG. 6. Schematic view (a) of NC, (b) efficiency versus the angle $\theta$ for NCs (squares dots) and bulk layer (circular dots) with the same volume (c) ratio of the efficiencies of $\mathrm{NCs}$ over bulk layer versus the angle $\theta$. 
approach shows that the best efficiency with the NCs is obtained with an angle of $70^{\circ}$ instead of $85^{\circ}$.

So, the main trends we found to obtain the best efficiency are (i) a ratio $\mathrm{D} / \mathrm{P}$ of the order of $0.7-0.8$, independently of the length, (ii) the efficiency increases with length, (iii) a given $\mathrm{D} / \mathrm{P}$ must be used with a small diameter, (iv) NCs have a better optical behavior than MPs of the same length with a best angle for NCs sidewall with respect to bottom face in the order of $70^{\circ}$, compared to an equivalent bulk layer with the same volume. In the next part, we compare our simulations with experimental measurements on different MP arrays.

\section{EXPERIMENTAL RESULTS}

\section{A. Fabrication of the MPs or the NCs}

To fabricate micropillars (or nanocones), masks with suitable sizes should be deposited on the substrate. In this work, we choose silica balls as mask and the LangmuirBlodgett technique is used to deposit modified silica monolayer on the Si substrate (with a $405 \mu \mathrm{m}$ thickness), due to their lower-cost compared with photoresist and photolithography. For a desired MPs diameter and period, the initial diameter of the silica balls gives the period and the diameter after etching gives the MPs diameter. Two types of silica balls with the diameter of $880 \mathrm{~nm}$ and $380 \mathrm{~nm}$ bought from Gmbh Microparticles company are used. To satisfy the needs of LB techniques and obtain amphiphilic silica balls, surface modification is required. The experimental process is: (1) 1 ML of silica ball solution (5\% in water) is centrifugalized at $5000 \mathrm{rpm}$ for $4 \mathrm{~min}$. After that, the supernatant is removed and replaced by $1.5 \mathrm{ml}$ of ethanol. This new solution is put in the ultrasonic bath to be well dispersed and then is centrifugalized again to remove the supernatant and replaced by ethanol, (2) $10 \mu \mathrm{l}$ of aminopropyl-dimethyl-ethoxy silane is put into the solution to react with particles for $24 \mathrm{~h}$ at room temperature, (3) centrifugal and ultrasonic processes, as step (1), are repeated three times. The modified silica balls are diluted into the mixture of $250 \mu \mathrm{l}$ ethanol and $250 \mu \mathrm{l}$ chloroform. Thanks to the amphiphilic nature of modified silica balls, when silica balls spread at the air/water interface, the hydrophilic group is immersed in the water and hydrophobic part is pointing towards air. The monolayer can be compressed by the barrier moving system, meanwhile, the surface pressure is measured by electrobalance.

Silica balls can be transferred into the substrate by successively dipping the substrate down and up through the monolayer under a constant surface pressure (pressure of dip-coating). Any contamination will lower surface tension, so the cleaning steps are performed before deposition process: chloroform, isopropanol, and deionized water are used successively to wash the LB trough.

In order to obtain nanopillars (or nanocones) with required diameters, silica balls were reduced in diameter by RIE plasma etching. In this work, we use $\mathrm{CHF}_{3}$ and $\mathrm{O}_{2}$ to etch silica balls, the parameters of the plasma are given in Table I. Fig. 7 shows the morphology of reduced silica balls with different parameters. The variation of power and pressure will result in the diameter change of silica balls. When silica balls have been reduced to a required size, DRIE or
TABLE I. RIE parameter for etching silica balls.

\begin{tabular}{ccccc}
\hline \hline & $\mathrm{CHF}_{3}(\mathrm{sccm})$ & $\mathrm{O}_{2}(\mathrm{sccm})$ & Power $(\mathrm{W})$ & Pressure (mTorr) \\
\hline $\mathrm{a}$ & 40 & 8 & 50 & 300 \\
$\mathrm{~b}$ & 40 & 8 & 70 & 350 \\
$\mathrm{c}$ & 40 & 8 & 100 & 550 \\
$\mathrm{~d}$ & 40 & 8 & 100 & 250 \\
\hline \hline
\end{tabular}

RIE etchings are subsequently used to fabricate micropillars and nanocones, respectively. The etching technique used in this work is Bosch $^{\mathrm{TM}}$ process, which is also called time-multiplex etching process, alternating between etching step and passivation step and then repeating them until the required length is reached. Etching is done using SF6/O $\mathrm{O}_{2}$, and passivation is performed under $\mathrm{C}_{4} \mathrm{~F}_{8}$ plasma. This step will deposit polymer on the surface, protecting the sidewall from etching. But etching step will completely remove polymer on the bottom and partially remove the polymer on the sidewall. ${ }^{40}$ This process produces structure with highly anisotropy at a higher etch rate, but the apparent drawback is the scallop profiles sidewall, as illustrated in Fig. 8(a). The etching parameters are given in Table II. ICP-RIE systems is RIE system with ICP generator applying a high density of ions which enhances the etching rate, along with RF generator to supply an electrical field near the sample to increase the degree of anisotropy. In this work, $\mathrm{Cl}_{2}$ is used to fabricate $\mathrm{Si}$ micropillars with smooth sidewalls, as shown in Fig. 8(b). The etching parameters are flux of $\mathrm{Cl}_{2}(30 \mathrm{sccm})$, pressure of $10 \mathrm{mTorr}$, and power of $40 \mathrm{~W}$. RIE system is used to fabricate nanocones. Fig. 9 is an illustration of the morphology of nanocones obtained by RIE etching with the following parameters: $\mathrm{CHF}_{3}(40 \mathrm{sccm}), \mathrm{O}_{2}(8 \mathrm{sccm})$, power $(100 \mathrm{~W})$, and a pressure of $250 \mathrm{mTorr}$. Finally, after etching, we remove the remaining silica balls by immersing them into $\mathrm{HF}$ solution $(50 \% \mathrm{HF})$ for $30 \mathrm{~s}$.

Fig. 10 is an illustration of Si MPs with different D/P made by ICP etching. The length is $1300 \mathrm{~nm}$, with a period of $380 \mathrm{~nm}$ and diameter of (a) $240 \mathrm{~nm}$ and (b) $320 \mathrm{~nm}$, respectively, and the length is $1300 \mathrm{~nm}$, period of $880 \mathrm{~nm}$ and diameter of (c) $520 \mathrm{~nm}$ and (d) $630 \mathrm{~nm}$, respectively.

Fig. 11 presents the corresponding reflectance spectra of these Si MPs in the wavelength range of $300-1000 \mathrm{~nm}$. In the range from $700 \mathrm{~nm}$ to $1000 \mathrm{~nm}$, the reflectance spectra of Si MPs with different $\mathrm{D} / \mathrm{P}$ are similar. However, in the range from $300 \mathrm{~nm}$ to $700 \mathrm{~nm}$, Si MPs with $\mathrm{D} / \mathrm{P}=0.6$ show clearly the smallest reflectance. When this ratio increases, the reflectance increases with a best fabricated MPs of around $\mathrm{D} / \mathrm{P}=0.6-0.7$. Comparing the reflectance spectra of MPs with a same $\mathrm{D} / \mathrm{P}=0.6$, i.e., diameter of $240 \mathrm{~nm}$ with period of $380 \mathrm{~nm}$ and diameter of $520 \mathrm{~nm}$ with period of $880 \mathrm{~nm}$, we can observe that the MPs with smaller diameter and smaller period present a lower reflectance.

\section{B. Comparison between experimental and simulation results}

In order to compare easily the measured and calculated reflectances which can exhibit some oscillations due to 

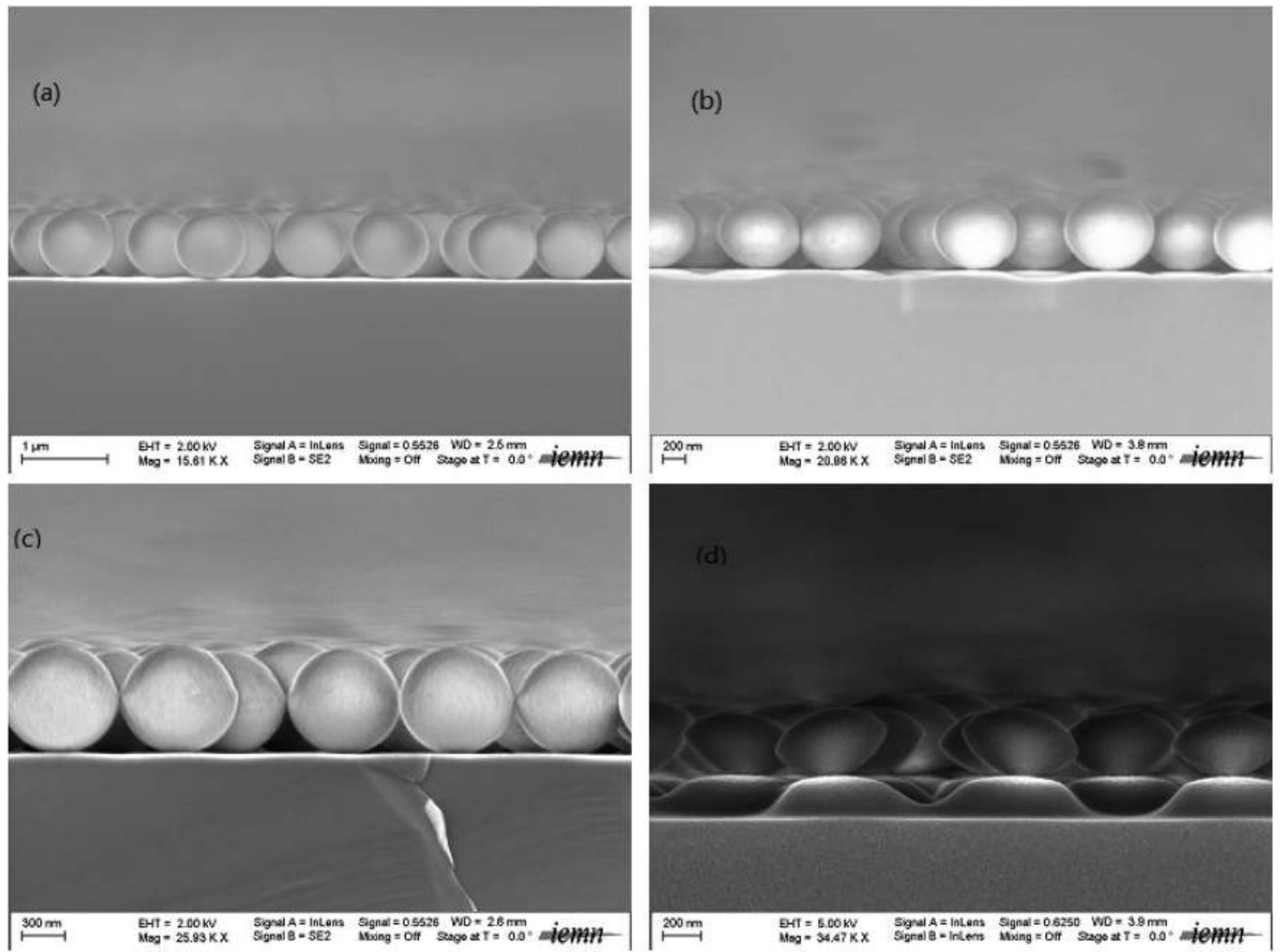

FIG. 7. SEM images of reduced silica balls with different etching parameter, images (a), (b), (c) and (d) correspond to parameters a, b, c, d in Table I, respectively.

interference phenomena associated with the MPs array, we have taken the average reflectances over 300 to $1200 \mathrm{~nm}$. The first comparison concerns the reflectance versus the diameter as illustrated in Fig. 12, with MPs having a $750 \mathrm{~nm}$ length and a period of $380 \mathrm{~nm}$. The experimental and theoretical average reflectance values exhibit the same behavior versus the diameter. With the increase of diameters, the average reflectance first decreases and then increases. The simulated results show that the best MPs have a diameter of
$270 \mathrm{~nm}$ with $\mathrm{D} / \mathrm{P}=0.7$, in agreement with experimental results. In any cases, the experimental reflectance is typically more or less $10 \%$ above the theoretical one (and this will appear in the next comparisons as well). In fact, as we use double faced polished silicon wafer, we believe that part of the light in near IR is reflected from the bottom face and then we measure a reflected signal a little greater than the theoretical one for which this experimental characteristics is not taken into account.
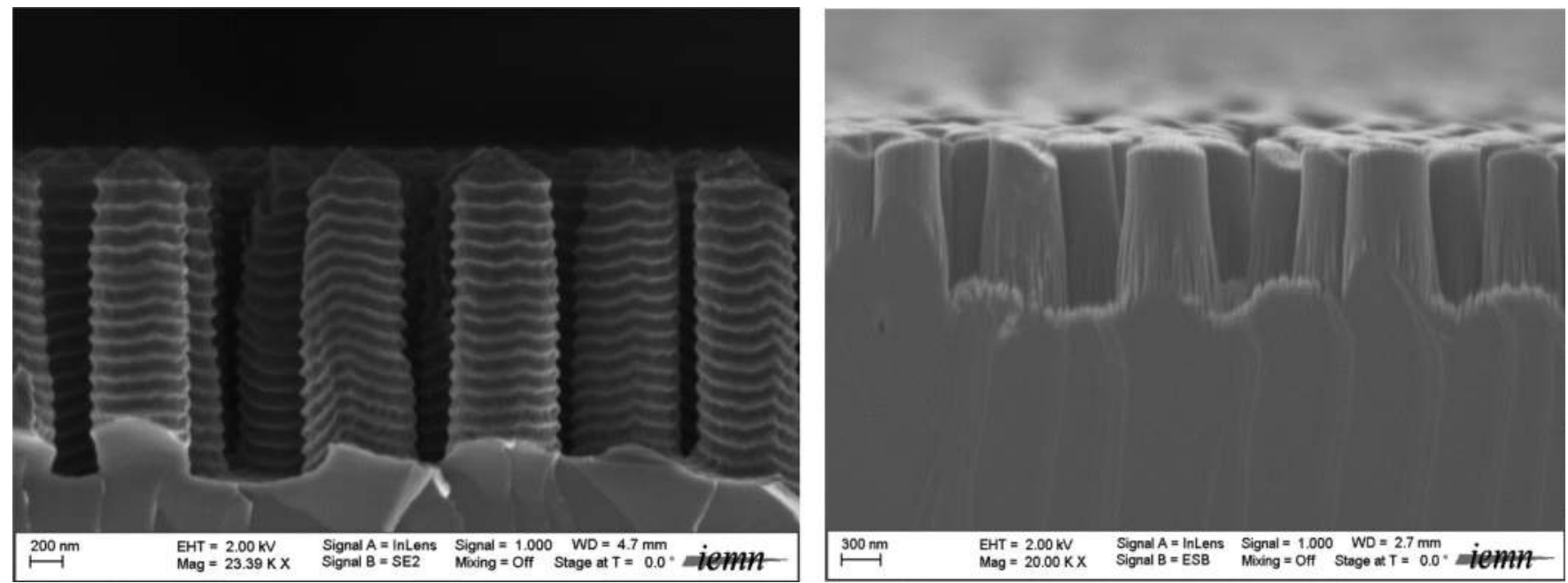

FIG. 8. SEM images of Si micropillars made by (a) DRIE etching and (b) ICP etching. 
TABLE II. DRIE parameter for fabricating Si micropillars shown in Figure 8.

\begin{tabular}{lccc}
\hline \hline Etching time (s) & $\mathrm{SF}_{3}(\mathrm{sccm})$ & $\mathrm{O}_{2}(\mathrm{sccm})$ & $\begin{array}{c}\text { Etching } \\
\text { power }(\mathrm{W})\end{array}$ \\
\hline 2 & 450 & 45 & 2100 \\
Passivation time (s) & $\mathrm{CHF}_{3}(\mathrm{sccm})$ & Passivation power $(\mathrm{W})$ & \\
2.6 & 200 & 2000 & \\
\hline \hline
\end{tabular}
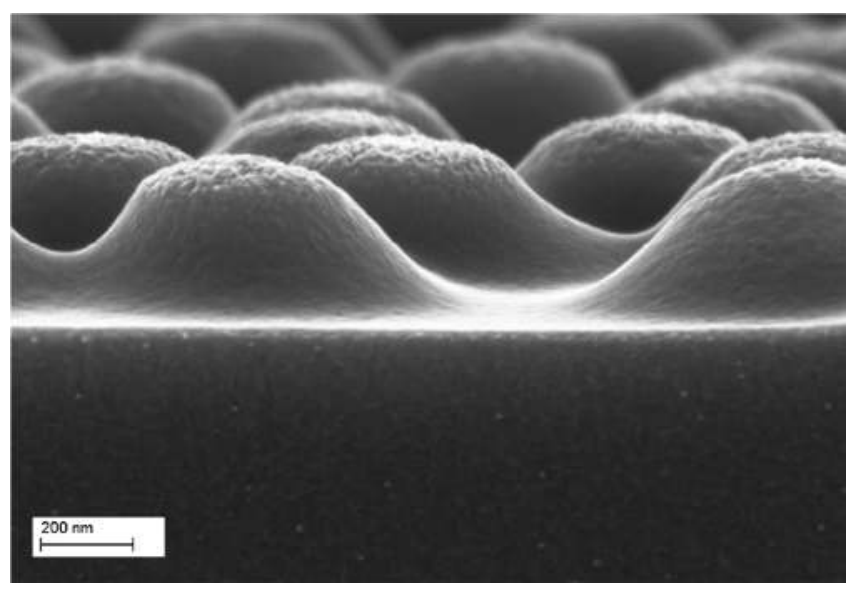

FIG. 9. SEM images of Si nanocones made by RIE etching.
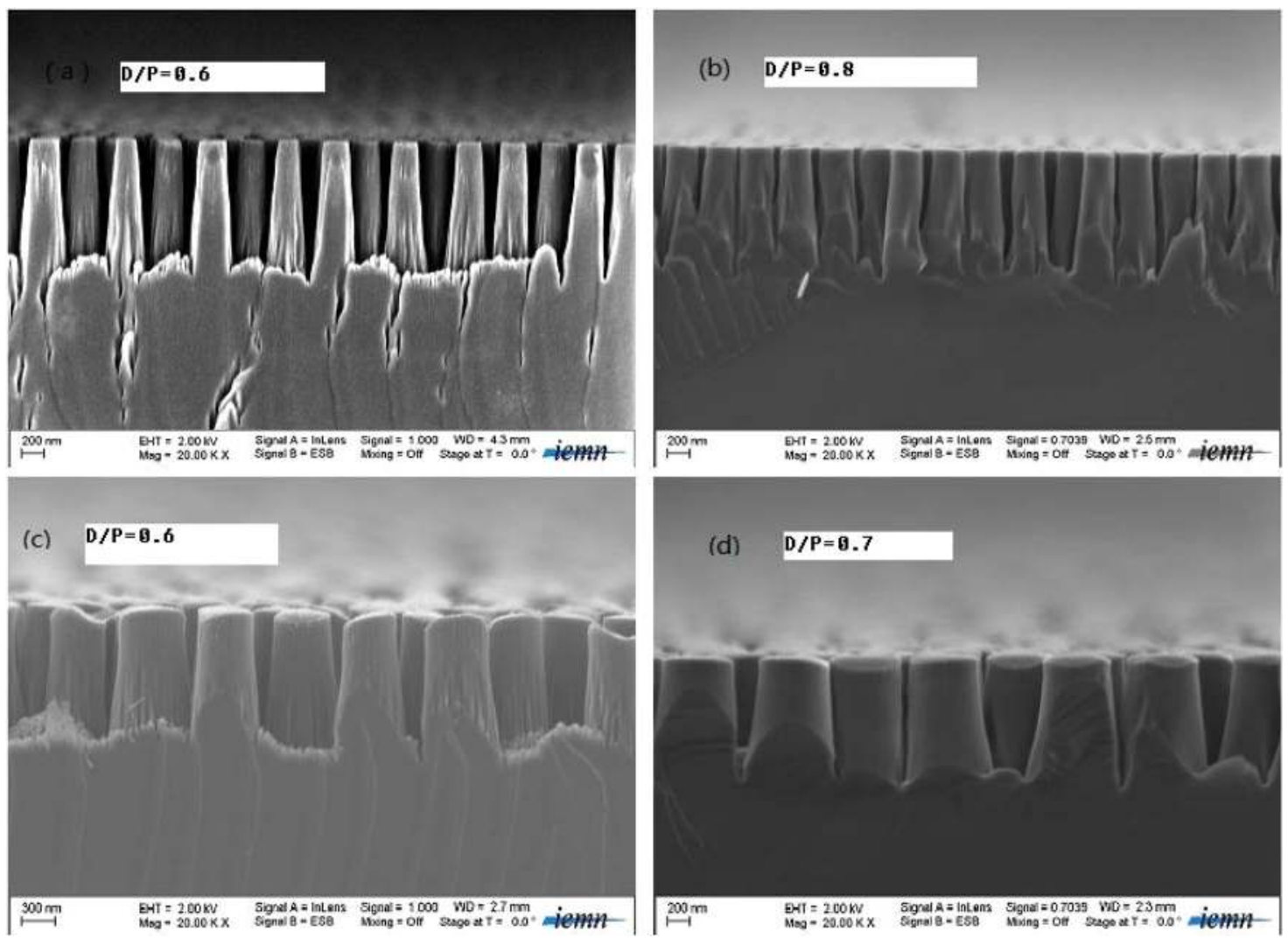

Next, we compare the simulated and measured reflectance spectra of MPs with the same length of $1300 \mathrm{~nm}$ and different $\mathrm{D} / \mathrm{P}$ of $0.6,0.7$, and 0.8 , as shown in Fig. 13. As pointed out in the previous paragraph, the calculated results are always smaller than the experimental results, but the average reflectance behavior as a function of $\mathrm{D} / \mathrm{P}$ is quite similar. It can be seen that the MPs with $\mathrm{D} / \mathrm{P}=0.6$ show the lower reflectance and when we compare the reflectance of MPs with $\mathrm{D} / \mathrm{P}=0.6$, the MPs with smaller period of $380 \mathrm{~nm}$ and smaller diameter of $240 \mathrm{~nm}$ have the lowest reflectance. So, the best MPs have the $\mathrm{D} / \mathrm{P}=0.6$, diameter of $240 \mathrm{~nm}$, and period of $380 \mathrm{~nm}$, which agrees with the experimental results. Finally, we simulated the reflectance of Si MPs with different lengths of $800 \mathrm{~nm}$, $1300 \mathrm{~nm}$, and $1900 \mathrm{~nm}$. Fig. 14 gives the average reflectance of simulated results, compared with experimental results. It can be seen that the reflectance first decreases as the length increases (i.e., the efficiency increases with the length) and, for higher length values (typically in this case $800 \mathrm{~nm}$ ), the average reflectance becomes a constant. So, the associated variation of the yield compared to bulk wafer decreases, as observed in the previous simulations. We note that for lengths around $2000 \mathrm{~nm}$, there is a good agreement between experimental and simulated reflectance. For this high value of the length, the effect of the reflection of the light on the polished back face has a weak importance because the photons are scattered and absorbed before they enter the substrate and not when they return.

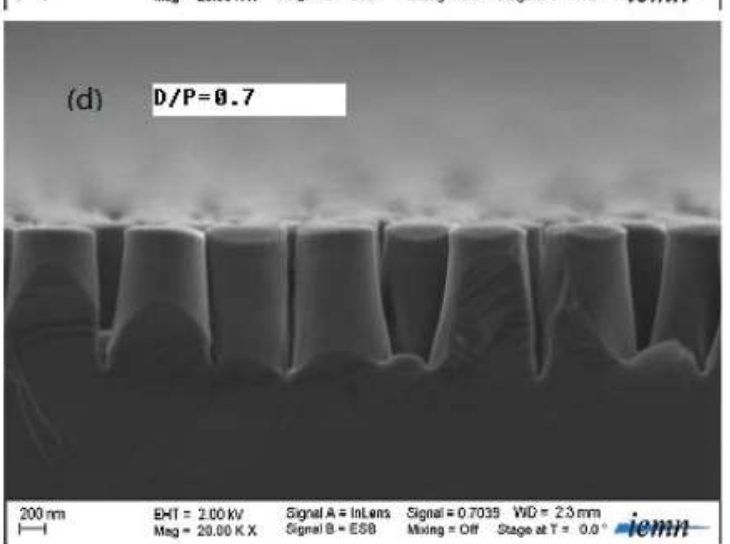

FIG. 10. Illustration of Si MPs made by ICP etching with different D/P. Fig. 10 is an illustration of Si MPs with different D/P made by ICP etching. The length is $1300 \mathrm{~nm}$, with a period of $380 \mathrm{~nm}$ and diameter of (a) $240 \mathrm{~nm}$ and (b) $320 \mathrm{~nm}$, respectively, and the length is $1300 \mathrm{~nm}$, period of $880 \mathrm{~nm}$, and diameter of (c) $520 \mathrm{~nm}$ and (d) $630 \mathrm{~nm}$, respectively. 


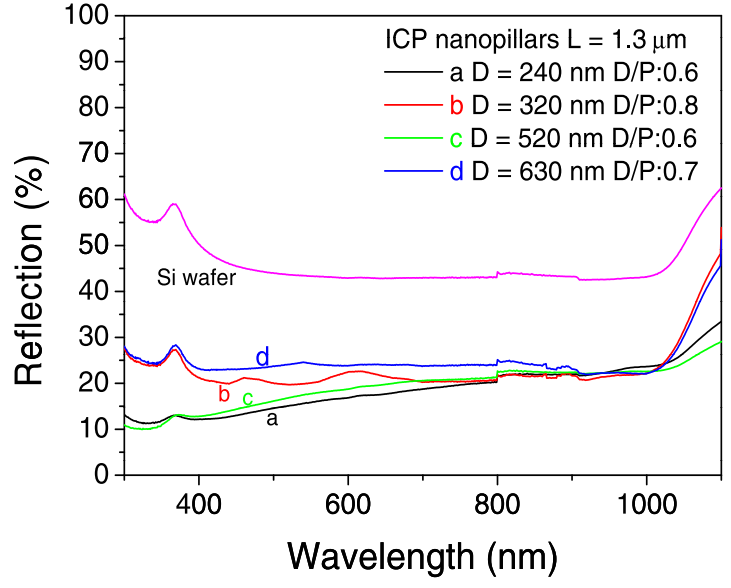

FIG. 11. Total reflectance spectra for Si MPs film with different D/P, (a), (b), (c), and (d) are corresponding to the Si MPs in Fig. 11.

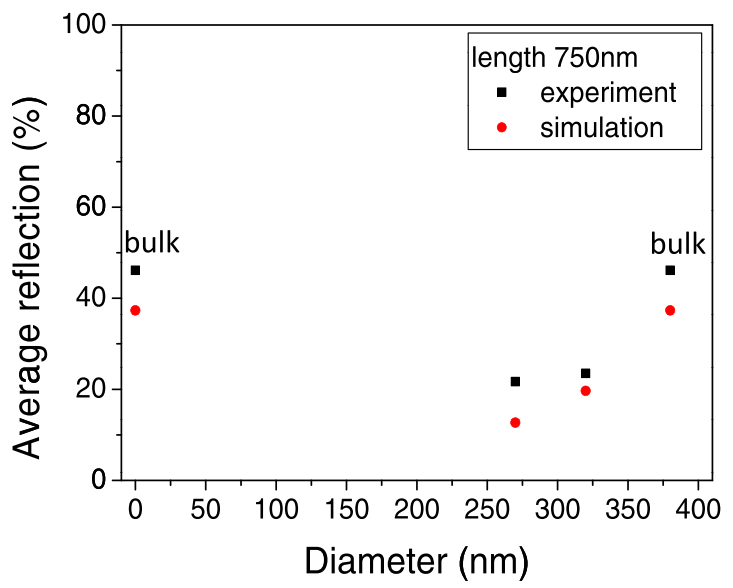

FIG. 12. Experimental (black squares) and theoretical (red squares) average reflectance as a function of diameters. MPs have the same length of $750 \mathrm{~nm}$, same period of $380 \mathrm{~nm}$, and different diameters of $320 \mathrm{~nm}$ and $270 \mathrm{~nm}$.

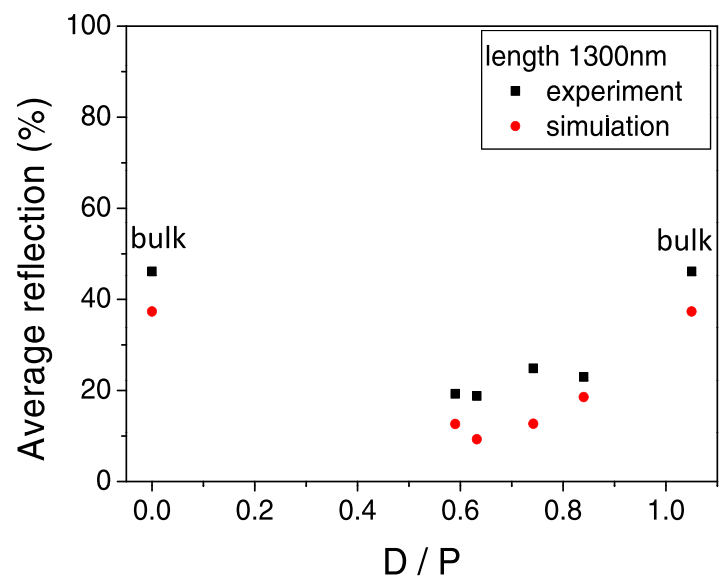

FIG. 13. Experimental (black squares) and theoretical (red squares) average reflectance as a function of D/P. MPs have the same length of $1300 \mathrm{~nm}$ and different $\mathrm{D} / \mathrm{P}$.

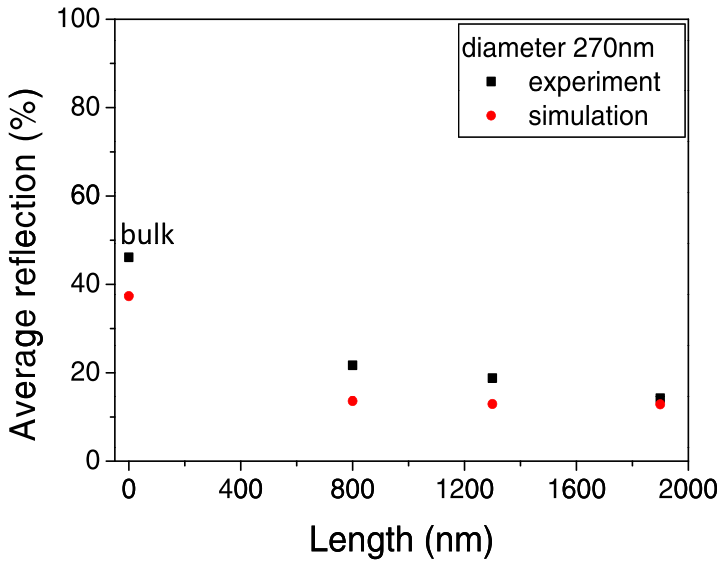

FIG. 14. Experimental (black squares) and theoretical (red squares) average reflectance as a function of length. MPs have the same diameters of $270 \mathrm{~nm}$ and same period of $380 \mathrm{~nm}$.

\section{CONCLUSION}

We have studied the influence of diameter, period, and length of MPs and NCs on their experimental and calculated optical properties for photovoltaic applications. More precisely, (a) the optimized diameter changes with the variation of period. When $\mathrm{D} / \mathrm{P}=0.6-0.8$, the MPs show the highest efficiency, and this ratio is independent of the length. (b) For a given ratio D/P, MPs with smaller diameters and periods exhibited highest efficiencies. (c) The longer the length, the higher the efficiency. This enhancement is due to both the increasing of $\mathrm{Si}$ volume and the surface structuration effect. When the length is high, the gain of structural effect is constant, so the enhancement is consequently due to the increase of Si volume. (d) When the size of the sidewalls is smaller than the measured wavelength, the sidewalls have no effect on the reflectance spectra of MPs. (e) If the bottom diameter, period, and height are constant, NCs with an angle $\theta$ of the order of $70^{\circ}$ have the highest efficiency. Finally, we have obtained a good agreement between the simulated and experimental reflectance spectra of a few Si MP arrays.

The surface morphology of the MPs/NCs and the effect of the surface passivation were not presented in details in this paper. They are under study (more on electrical properties since recombination centers play a key role in the efficiency of solar cells) and will be published elsewhere.

\section{ACKNOWLEDGMENTS}

This work was partly supported the Ministry of Higher Education and Research, Nord-Pas de Calais Regional Council and FEDER through the "Contrat de Projets Etat Region (CPER) 2007-2013," as well as by the "GENESE" contract (Ref.: 13-BS09-0020-03) from the Agence Nationale de la Recherche, ANR. Di Zhou has a Ph.D. grant from the People's Republic of China. T. Xu acknowledges support from the National Natural Science Foundation of China (61204014) and the Innovation Project of Education Commission of Shanghai Municipality (12YZ021). 
${ }^{1}$ H. Kind, H. Yan, B. Messer, M. Law, and P. D. Yang, Adv. Mater. 14, 158 (2002).

${ }^{2}$ F. Qian, Y. Li, S. Gradecak, D. Wang, C. J. Barrelet, and C. M. Lieber, Nano Lett. 4, 1975 (2004).

${ }^{3}$ B. Tian, X. Zheng, T. J. Kempa, Y. Fang, N. Yu, G. Yu, J. Huang, and C. M. Lieber, Nature 449, 885 (2007).

${ }^{4}$ N. A. Sanford, P. T. Blanchard, K. A. Bertness, B. Tian, L. Mansfield, J. B. Schlager, A. W. Sanders, A. Roshko, B. B. Burton, and S. M. Geroge, J. Appl. Phys. 107, 034318 (2010).

${ }^{5}$ A. De Luna Bugallo, M. Tchernycheva, G. Jacopin, L. Rigutti, F. H. Julien, S.-T. Chou, Y.-T. Lin, P.-H. Tseng, and L.-W. Tu, Nanotechnology 21, 315201 (2010).

${ }^{6}$ B. M. Kayes, H. A. Atwater, and N. S. Lewis, J. Appl. Phys. 97, 114302 (2005).

${ }^{7}$ L. Cao, P. Fan, A. P. Vasudev, J. S. White, Z. Yu, W. Cai, J. A. Schuller, S. Fan, and M. L. Brongersma, Nano Lett. 10, 439 (2010).

${ }^{8}$ T. Xu, Y. Lambert, B. Grandidier, D. Stiévenard, A. Akjouj, Y. Pennec, and B. Djafari-Rouhani, J. Appl. Phys. 112, 033506 (2012).

${ }^{9}$ G. Brönstrup, N. Jahr, C. Leiterer, A. Csaki, W. Fritzsche, and S. Christiansen, ACS Nano 4(12), 7113 (2010).

${ }^{10}$ E. C. Garnett and P. D. Yang, J. Am. Chem. Soc. 130, 9224 (2008).

${ }^{11}$ M. D. Kelzenberg, S. W. Boettcher, J. A. Petykiewicz, D. B. TurnerEvans, M. C. Putnam, E. L. Warren, J. M. Spurgeon, R. M. Briggs, N. S. Lewis, and H. A. Atwater, Nature Mater. 9, 368 (2010).

${ }^{12}$ J. Zhu, Z. Yu, G. D. Burkhard, C.-M. Hsu, S. T. Connor, Y. Xu, Q. Wang, M. McGehee, S. Fan, and Y. Cui, Nano Lett. 9, 279 (2009).

${ }^{13}$ L. Tsakalatos, J. Balch, J. Fronheiser, M.-Y. Shih, S. F. Leboeuf, M. Pietrzykowski, P. J. Codella, B. A. Korevaar, O. Sulima, J. Rand, A. Davuluru, and U. Rapol, J. Nanophoton. 1, 013552 (2007).

${ }^{14}$ L. Tsakalakos, Mater. Sci. Eng., R 62, 175 (2008).

${ }^{15}$ M. C. Putnam, S. W. Boettcher, M. D. Kelzenberg, D. B. Turner-Evans, J. M. Spurgeon, L. E. Warren, R. M. Briggs, N. S. Lewis, and H. A. Atwater, Energy Environ. Sci. 3, 1037 (2010).

${ }^{16}$ J. Zhu, Z. Yu, S. Fan, and Y. Cui, Mater. Sci. Eng., R 70, 330 (2010).

${ }^{17}$ Y. Liu, S. H. Sun, J. Xu, L. Zhao, H. C. Sun, J. Li, W. W. Mu, L. Xu, and K. J. Chen, Opt. Express 19, A1051 (2011).

${ }^{18}$ K. Q. Peng and S.-T. Lee, Adv. Mater. 23, 198 (2011).
${ }^{19}$ M. Farangi, M. Zahedifar, M. R. Mozdianfard, and M. H. Pakzamir, Appl. Phys. A 109, 299 (2012).

${ }^{20}$ Q. Lin, B. Hua, S.-F. Leung, X. Duan, and Z. Fan, ACS Nano 7, 2725 (2013).

${ }^{21}$ J.-Y. Jung, H.-D. Um, S.-W. Jee, K.-T. Park, J. H. Bang, and J.-H. Lee, Sol. Energy Mater. Sol. Cells 112, 84 (2013).

${ }^{22}$ H. Tan, E. Psomadaki, O. Isabella, M. Fischer, P. Babal, R. Vasudevan, M. Zeman, and A. H. M. Smets, Appl. Phys. Lett. 103, 173905 (2013).

${ }^{23}$ L. Hu and G. Chen, Nano Lett. 7, 3249 (2007).

${ }^{24}$ C. Lin and M. L. Povinelli, Opt. Express 17, 19371 (2009).

${ }^{25}$ J. Li, H. Yu, S. M. Wong, X. Li, G. Zhang, P. Guo-Qiang Lo, and D.-L. Kwong, Appl. Phys. Lett. 95, 033102 (2009).

${ }^{26}$ J. Li, H. Yu, S. M. Wong, X. Li, G. Zhang, P. Guo-Qiang Lo, and D.-L. Kwong, Appl. Phys. Lett. 95, 243113 (2009).

${ }^{27}$ J. Zhu, C.-M. Hsu, Z. Yu, S. Fan, and Y. Cui, Nano Lett. 10, 1979 (2010).

${ }^{28}$ S. E. Han and G. Chen, Nano Lett. 10, 1012 (2010).

${ }^{29}$ S. E. Han and G. Chen, Nano Lett. 10, 4692 (2010).

${ }^{30}$ W. Q. Xie, J. I. Oh, and W. Z. Shen, Nanotechnology 22, 065704 (2011).

${ }^{31}$ Z. Yu, A. Raman, and S. Fan, Appl. Phys. A 105, 329 (2011).

${ }^{32}$ B. Wang and P. W. Leu, Nanotechnology 23, 194003 (2012).

${ }^{33}$ B. C. P. Sturmberg, K. B. Dossou, L. C. Botten, A. A. Asatryan, C. G. Poulton, R. C. McPhedran, and C. Martijn de Sterke, Appl. Phys. Lett. 101, 173902 (2012).

${ }^{34}$ W. Wang, J. Zhang, Z. Xie, and G. Qin, J. Phys. D: Appl. Phys. 46, 195106 (2013).

${ }^{35}$ K. X. Wang, Z. Yu, V. Liu, Y. Cui, and S. Fan, Nano Lett. 12, 1616 (2012).

${ }^{36}$ M. Boccard, C. Battaglia, F.-J. Haug, M. Despeisse, and C. Ballif, Appl. Phys. Lett. 101, 151105 (2012).

${ }^{37}$ J. P. Berenger, J. Comput. Phys. 114, 185 (1994).

${ }^{38}$ R. M. A. Azzam and N. M. Basharra, Ellipsometry and Polarized Light (North-Holland, Amsterdam, 1977).

${ }^{39}$ L. Ding, T. P. Chen, Y. Liu, C. Y. Ng, and S. Fung, Phys. Rev. B 72, 125419 (2005).

${ }^{40}$ B. Wu, A. Kumar, and S. Pamarthy, J. Appl. Phys. 108, 051101 (2010). 